\title{
Modeling of Coastal Upwelling Using Spatiogram and Structuring Elements
}

\author{
Yus Sholva \\ Informatics Department, \\ Engineering Faculty \\ University of Tanjungpura \\ Pontianak, Indonesia \\ sholvariza@yahoo.com
}

\author{
Benhard Sitohang \\ School of Electrical Engineering and \\ Informatics \\ Bandung Institute of Technology \\ Bandung, Indonesia \\ benhard@stei.itb.ac.id
}

\author{
Ketut Wikantika \\ Faculty of Earth Sciences and \\ Technology \\ Bandung Institute of Technology \\ Bandung, Indonesia \\ ketut@gd.itb.ac.id
}

\begin{abstract}
Upwelling is an oceanographic phenomenon where the mass of water from the sea floor, cold temperature and nutrient rich, moving up to the sea surface. Upwelling could be happened due to the interaction between the surface water with the wind, ocean currents, Ekman transport, and the Coriolis force, so there is a special characteristic of the upwelling waters. Nevertheless, a common indicator of upwelling is the sea surface temperature (SST) lower than the surrounding areas, high concentrations of chlorophyll-a, as well as high salinity and density. In coastal upwelling, a lower temperature will be detected near the coast, while warmer temperatures towards offshore. This condition leads to form unique patterns contour of sea surface temperature. By using the data of SST derived from satellites, SST can be represented with the color and/or contour. Each color pixel value represents a particular SST. The initial phase of this research is to develop a model for the identification of upwelling based on the pixel and contour patterns. By using sea surface temperature data, the average SST (each month) were analyzed and generate contour lines. Contour lines are formed from the pixels that have the same temperature value. By calculating the distance between pixels in the same temperature class and the distance to the surrounding pixels, we have been developing a model for the detection of upwelling.
\end{abstract}

Keywords-upwelling, sea surface temperature, contour pattern, pixel detection, spatiogram, structure elements.

\section{INTRODUCTION}

Mesoscale phenomena in oceanography, such as eddies, currents, fronts and upwelling regions has long been a goal of research especially related to global climate change, marine resources and fisheries. Many efforts were made to identify these oceanographic features both manual approach (visual) and automation.

Upwelling is a phenomenon in which the mass of water from the ocean floor moves up toward the surface, it's colder than the temperature of the surface and contains a lot of nutrients. Upwelling regions have temperature fields distinctly lower than the water surrounding them. In coastal upwelling, a lower temperature will be detected near the coast, while warmer temperatures towards offshore. This condition leads to form unique contour patterns of sea surface temperature [1].

In general upwelling covers a wide area of sea, for fishing purposes; the identification of the location of upwelling in this region is less useful. Fishermen have to catch a fish in a wide area, result in high operational cost. Therefore, the determination of upwelling in the waters of a small area is needed.

Investigation and identification of unique characteristics (specific) of upwelling based on the contour patterns in certain regions, it is very necessary. It is known that upwellings in certain waters are different from each other even in the same waters. Because upwelling is varied temporally (by time) in which the elements that cause upwelling as wind pressure, ocean currents, temperature, salinity also have high variability. This is a challenge in identifying patterns of upwelling because it could be no unique pattern.

Identification of upwelling can be done by analyzing at least two oceanographic parameters, i.e. sea surface temperature (SST) and chlorophyll-a concentration (Chl-a). Data from both SST and Chl-a can be obtained from satellite remote sensing such as MODIS Aqua and Terra MODIS are available for free.

Identification of upwelling has been done in several Indonesian waters, more specifically in the waters south of Java, studies have been carried out by [2][3][4]. Upwelling process in the southern waters of Java influenced by oceanographic-atmospheric interactions originating from the Pacific Ocean and the Indian Ocean respectively the El Nino Southern oscillation (ENSO), the Indian Ocean Dipole (IOD) [5], sea surface current system, Indonesian cross currents (Arlindo) and monsoon [3].

As in that study, the analysis is carried out visual observations based on color and / or contour on the results of data processing SST and Chl-a, then the results described descriptively. This approach is very subjective because the determination of the location of upwelling depends on the interpretation of each researcher. Therefore in this study we developed a model to identify the upwelling using a combination of spatiogram and structure elements

\section{RELATED WORK}

\section{A. Upwelling Pattern}

References [6] have proposed an algorithm to automatically detect fronts with process-level pixel information and store the information as edge. The algorithm known as single image 
edge detection. It is difficult to apply this algorithm to interpret features such as eddies, upwelling areas, and squirts jets, vortices mushrooms etc., as applicable in certain cases [1].

In upwelling systems, these fronts occur between the cold, near-shore water and warmer offshore water, either as a relatively continuous alongshore front, or as plume-like structures, depending on the width of the continental shelf and/or the presence of topographic discontinuities such as capes. Upwelling frontal systems exhibit instabilities that generate other mesoscale and sub-mesoscale thermal structures, such as complex imbricate fronts and filaments, which are always associated with strong surface chlorophyll gradients [7].

Visually, an indicator of upwelling can be observed in the presence of high SST gradient than the surrounding temperature. The high gradient of SST due to extreme temperature changes from cold temperatures (as the center of mass upwelling) to warmer temperatures (it spreads to offshore). Fig. 1 shows upwelling represented by the color of sea surface temperature derived from satellite remote sensing data processing. Each pixel color in the image represents a particular temperature value.

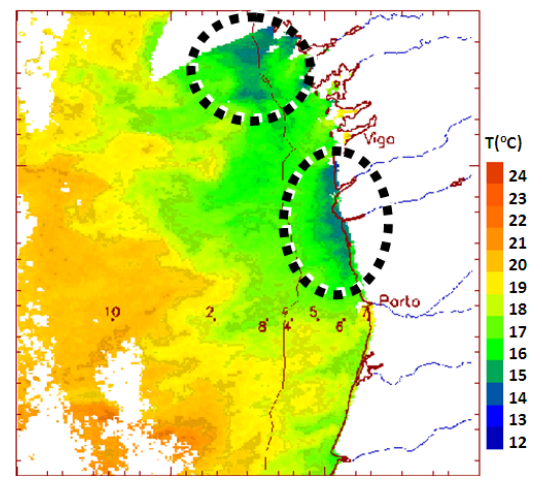

Figure 1. The sea surface temperature derived from satellite data. Cold temperature water is detected in the coastal upwelling signaling (dashed line) (Source: http://earth.esa.int/)

In addition to visualization of color, upwelling is visualized as contour lines SST. High density of contour line means temperature gradation is high (high temperature variability), meanwhile if density of contour line low means temperature gradation is low (temperature tends to homogeneous). Fig. 2 shows an example of (A) a high density of contour line and (B) low density of contour line. The less number of contour lines mean the value of SST tend to homogeneous in certain waters.

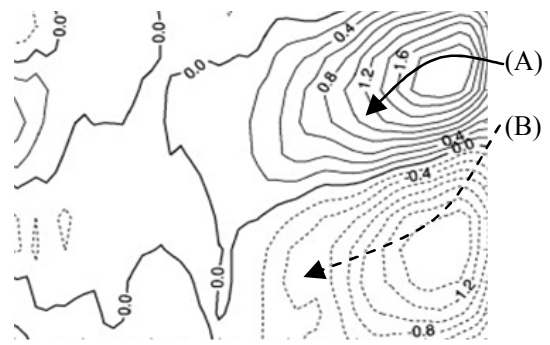

Figure 2. An example of visualization of the contour lines
Illustration upwelling visualized by color and contour lines are shown in Fig. 3, each pixel represents a certain temperature value (represented by colors), a set of pixels with the same value or approximately can be constructed into contour lines, it will form contour patterns that represent upwelling.

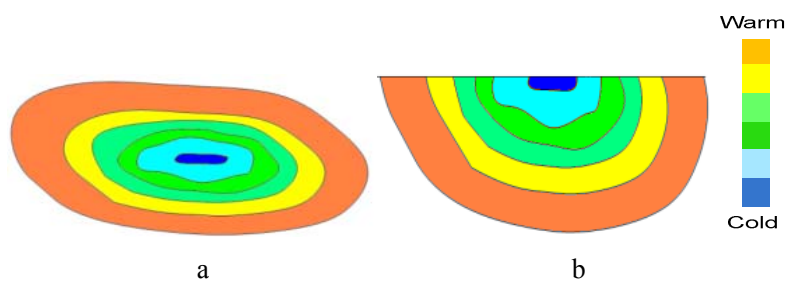

Figure 3. An illustration of sea surface temperature is represented by the color and contour lines (horizontal transect) (a) offshore upwelling (b) coastal upwelling

\section{B. Structuring Elements of Coastal Upwelling}

Coastal upwelling areas do not have a definitive shape as well as eddies, but since this area is a closed area so that the variation of the structural elements can be applied to detect them [1].

The following explanation gives a brief overview of the methods used by [1] for the detection of upwelling, which originally was applied in detection of eddies. Detection of upwelling regions begins by prompting user to specify the core temperature, boundary temperature, and a lateral distance estimate of these structures. These parameters form the basis for segmentation the dataset into regions with potential upwelling structures [1]. Segmentation is done by binary threshold based on the following equation:

$$
f_{T}(x, y)= \begin{cases}1, & \text { if } T_{C}<f(x, y)<T_{K} \\ 0, & \text { otherwise }\end{cases}
$$

Where $T_{K}$ is the background (or boundary) temperature, $T_{C}$ is the core temperature.

A $2 \times 2$ pixel mask is applied in the data threshold to eliminate the thin edge (thin edge) and obtain well-defined region. Each regional small insignificant called holes must be filled to obtain a better definition. Candidate region of interest is given as an input in the recognition systems of mesoscale features to locate the area of upwelling and eddies. Recognition system constructs a structuring element to perform feature detection [1].

Reference [1] have proposed a disk-shaped structural elements to compute center of mass for a possible upwelling region, as shown in Fig. 4 Structure of elements is a set of coordinates with a number of discrete points relative to some origin that specify a definite pattern.

The structure of the disk-shaped element (Fig. 4) was created to keep the length of the radius is analogous to that specific lateral distance. However, this distance is estimated by the user so that a measurement error is set $75 \%$ of the estimated distance. This means that all regions with a distance greater than $75 \%$ of the estimate can be considered as a potential region. 


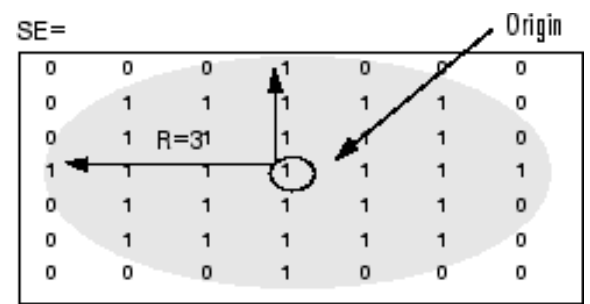

Figure 4. A structuring element (source: www.mathworks.com)

The center of mass is the start point detection which spread in all directions in order to determine the boundary upwelling, the placement of the points closer to the center of mass based on curve-fitting equation. Determination of the center of mass is based on the following equation:

$$
C_{x}=1 / k\left(\sum_{i=1}^{i=k} x_{i}\right), \quad C_{y}=1 / k\left(\sum_{j=1}^{j=k} y_{j}\right)
$$

where, $k=$ total number of points in the region; $x, y=x, y$ coordinate for each pixel in the region.

Curve-fitting algorithm is modeled using the following linear regression equation.

$$
y=a_{0}+a_{1} t
$$

where, $a_{0}=$ intercept; $a_{1}=$ slope; and $t=$ distance from the center of mass. Coefficients $a_{0}$ dan $a_{1}$ is calculated using the least squares after regression analysis.

\section{Spatiogram in Image}

Spatiogram is image histogram descriptor which combines the mean and variance of the position of each color, in other words spatiogram is a histogram with a moment of higherorder that not only saves the value of a pixel but also its spatial relationship. Spatiogram can be regarded as geometric models that bridge the gap in the histogram, which can be done any transformations like translation, similarity, affine, projective, or B-splines [8].

An image is a two-dimensional mapping $\mathrm{I}: \mathrm{x} \rightarrow \mathrm{v}$ from piksel $\mathrm{x}=[\mathrm{x}, \mathrm{y}] \mathrm{T}$ to value $\mathrm{v}$. The meaning of these values is arbitrary, they may represent raw gray-level intensities or component colors, or the result of preprocessing (quantization, color space transformation, wavelet coefficients, etc.). Reference [8] represents the second-order spatiogram of an image as

$$
h_{I}^{(2)}(b)=\left\langle n_{b}, \mu_{b}, \Sigma_{b}\right\rangle, b=1, \ldots, B
$$

where $n_{b}$ is the number of pixels whose value is that of the $b$ th bin, and $\mu_{b}$ and $\Sigma_{b}$ are the mean vector and covariance matrices, respectively, of the coordinates of those pixels.

The number $\mathrm{B}=|\mathrm{V}|$ is the number of bins in spatiogram. Notice that

$$
h_{I}^{(0)}(b)=n_{b}, \quad b=1, \ldots, B
$$

is actually the histogram of $\mathrm{I}$.

The similarity between two spatiograms can be computed as the weighted sum of the similarity between the two histogram:

$$
\rho\left(h, h^{\prime}\right)=\sum_{b=1}^{B} \psi_{b} \rho_{n}\left(n_{b}, n_{b}^{\prime}\right)
$$

For a zeroth-order spatiogram, $\psi_{b}=1$. For a second-order spatiogram, $\psi_{b}$ is set to the probability that $\bar{x}_{b}$ was drawn from a Gaussian distribution described by $\left(\bar{x}_{b}^{\prime}, \Sigma_{b}^{\prime}\right)$, multiplied by the probability in the reverse direction:

$$
\psi_{b}=\eta \exp \left\{-\frac{1}{2}\left(\mu_{b}-\mu_{b}^{\prime}\right)^{T} \hat{\Sigma}_{b}^{-1}\left(\mu_{b}-\mu_{b}^{\prime}\right)\right\}
$$

where $\eta$ is the Gaussian normalization constant and $\hat{\Sigma}_{b}^{-1}=\left(\left(\Sigma_{b}^{-1}+\left(\Sigma_{b}^{\prime}\right)^{-1}\right)\right.$. The value inside the summation is the average of the two Mahalanobis distances, one between $\mathrm{X}$ and $\mathrm{x}^{\prime}$ and the other between $\mathrm{x}^{\prime}$ dan $\mathrm{x}$.

The similarity between the histogram bins can be computed using any of a number of techniques, such as histogram intersection [8];

$$
\rho\left(n_{b}, n_{b}^{\prime}\right)=\frac{\min \left(n_{b}, n_{b}^{\prime}\right)}{\sum_{j=1}^{B} n_{j}}
$$

Or the Bhattacharyya coefficient:

$$
\rho\left(n_{b}, n_{b}^{\prime}\right)=\frac{\sqrt{\left(n_{b}, n_{b}^{\prime}\right)}}{\sqrt{\left(\sum_{j=1}^{B} n_{j}\right)\left(\sum_{j=1}^{B} n_{j}^{\prime}\right)}}
$$

A spatiogram captures the probability density function (PDF) of the image values:

$$
P(I(\mathrm{x})=v)=p(\mathrm{x}, v)=p(x \mid v) p(v))
$$

where, for a second-order spatiogram as

$$
\begin{gathered}
\rho(v)=\frac{n_{b}}{\sum_{j=1}^{B} n_{j}} \\
p(\mathrm{x} \mid v)=\eta \exp \left\{-\frac{1}{2}\left(\mathrm{x}-\mu_{k}\right)^{T} \Sigma_{b}^{-1}\left(\mathrm{x}-\mu_{k}\right)\right\},
\end{gathered}
$$

$\mathrm{v}$ is the value of the $b$ th bin, and $\eta$ is the Gaussian normalization constant as before. For a zeroth-order spatiogram (histogram), there is no spatial dependency and the joint PDF is 
equal to the marginal: $p(\mathrm{x}, v)=p(v)$. The reader can be referred to [8] and [9] for further explanation about spatiogram.

Reference [8] carried out experiments using the image of a human head with three poses as shown in Fig. 5, the histogram and spatiogram is calculated then used as the generative models to produce a new image of the same size as the original by sampling PDF given by (11) and (12). An RGB color space was used with 8 bins per channel, and only the diagonal elements of $\Sigma_{i}$ were used, with the variances clipped at 1 pixel in order to make $\Sigma_{i}$ invertible even for bins for which $\eta_{b}$ is 0 or 1 .

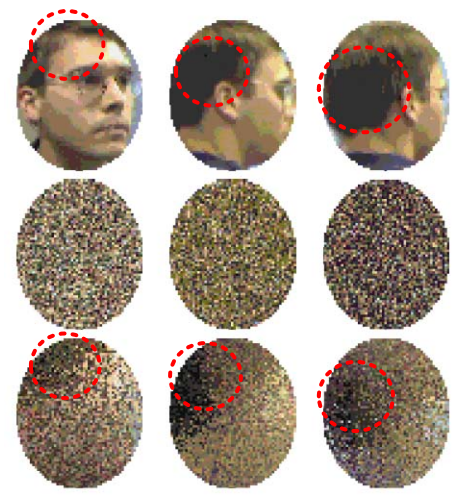

Figure 5. Three different poses of a person (top), with images generated from the histogram (middle) and spatiogram (bottom). The spatiogram captures spatial relationships among the colors, whereas the histogram discards all spatial information. (source: [8])

\section{Proposed ModeL}

\section{A. Region of Interest Detection}

The histogram is a graphical display of tabulated frequencies, in the field of image processing histogram tabulated the color or pixel of the image. Localization of upwelling areas cannot be approximated by a histogram because the histogram does not contain spatial information. Therefore to perform localization of upwelling region of interest we might use spatial histogram (spatiogram).

In waters observed, it is possible more than one upwelling regions detected as a candidate, then we can use spatiogram approach to locate the ROI of upwelling. As illustrated in Fig. 6 , there are several candidates ROI of upwelling in image.

References [10] have proposed method to determine upwelling region, if in candidate regions we found difference of sea water temperatures of $0.5{ }^{\circ} \mathrm{C}$ within a radius of 3 kilometers then those regions can be determined as upwelling regions. If we assume a temperature range between $24-27^{\circ} \mathrm{C}$ as the temperature corresponding to the fish habitat and if we set the class interval of temperature as $0.5{ }^{\circ} \mathrm{C}$ then there are 7 classes of temperature. Thus the region of interest (ROI) of upwelling can be defined as $21 \mathrm{~km}(3 \mathrm{~km} \times 7)$ in radius.

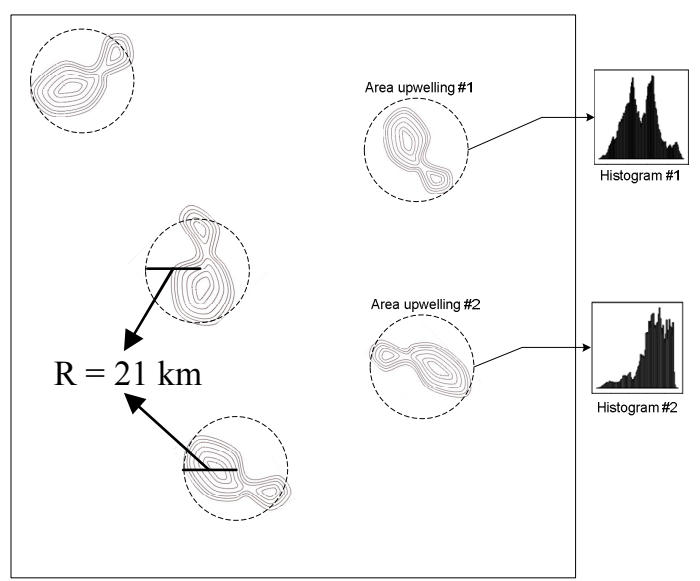

Figure 6. Illustrated the candidate of ROI upwelling is segmented using spatiogram approach. We set length of radius in $21 \mathrm{~km}$ as initial state for each region.

\section{B. Upwelling Detection Model}

In the previous section, we explained about ROI detection as a candidate upwelling regions. Then each candidate will be determined whether the upwelling occurs or not.

An early condition of waters before upwelling as depicted Fig. 7, where the temperature is warmer at surface layer and relatively homogeneous than the layer under. Each temperature value is represented by a colored circle. When upwelling occurs, the water mass from the bottom rise up to the surface, this shown by upward movement of circles gradually, as illustrated in Fig. 7b, 7c, 7d. The colors - yellow, green, light blue and blue - represent as low temperature. At the end the process, circles colored as yellow, green, light blue, and blue will occupy the surface layer near coast line.

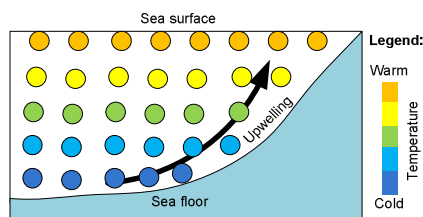

(a)

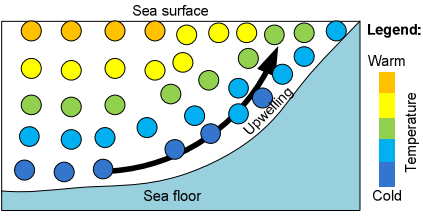

(c)

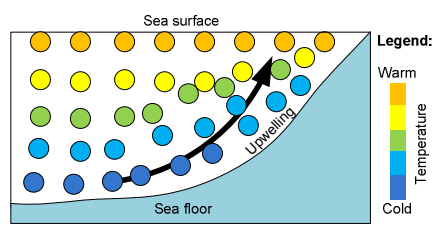

(b)

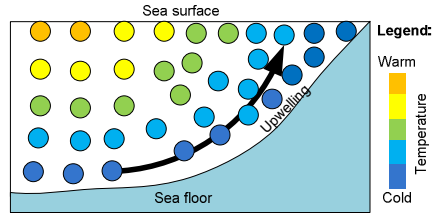

(d)
Figure 7. Vertical transects of coastal waters that demonstrated upwelling process in sequence. Colored circles represented differences temperature on each layer at coastal waters.

Then we analyzed horizontal transect of coastal waters and construct a model of upwelling system according to colored circles, as depicted in Fig. 8. Colored circles that represented as cold SST occupy near coastline and the circles that represented as warmer SST move outward to the offshore. It is clear that proposed model represent a real condition of the upwelling 
system. In this illustration pixel of SST is represented by the circle (Fig. 7 and Fig. 8).

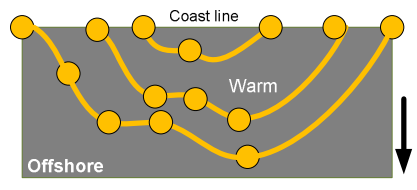

(a)

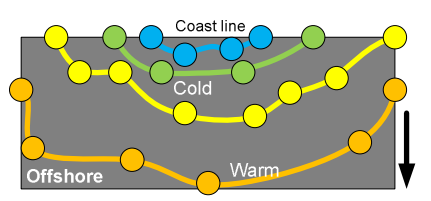

(c)

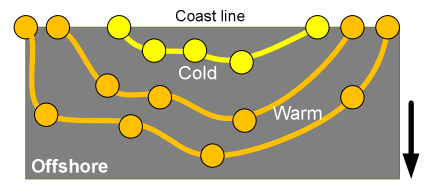

(b)

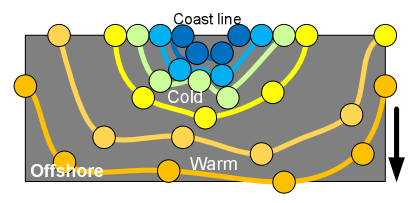

(d)
Figure 8. Horizontal transect of coastal waters that illustrate the movement of warm water mass from the coast towards offshore when upwelling occurs, it replaced by the cold water masses at coastal waters.

This model is similar to the model of the disk-shaped structure elements used by [1], but in this model the user does not need to set the initial value of core temperature, temperature limits, the lateral distance from the alleged upwelling areas.

Based on this modeling, the waters of which allegedly occurred coastal upwelling waters that have temperatures are cooler waters on the coast (at the center of mass) and the temperature warmer waters off the coast. In Fig. 9 shows the pixels detection process around the center of mass.

As explained before, if sea surface temperature that suit for fish is ranging from 24 to $27^{\circ} \mathrm{C}$ and class interval is $0.5^{\circ} \mathrm{C}$ so we have 7 classes of sea surface temperature. Each class of SST is converted to distance approximate to $3 \mathrm{~km}$ thus we have the estimation distance for candidate of ROI is $21 \mathrm{~km}$ as radius. While iterating process found the pixels around the center of mass has a value in the range of temperatures $24-27^{\circ} \mathrm{C}$, it can be determined that the candidate region is an area of upwelling.

Detection of pixels starting from the center of mass outward in all directions as shown in Fig. 9, if we use the data from the satellite Aqua / Terra which has a spatial resolution of $250 \mathrm{~m}$, a distance of $7 \mathrm{~km}$ radius equivalent to 28 pixels.

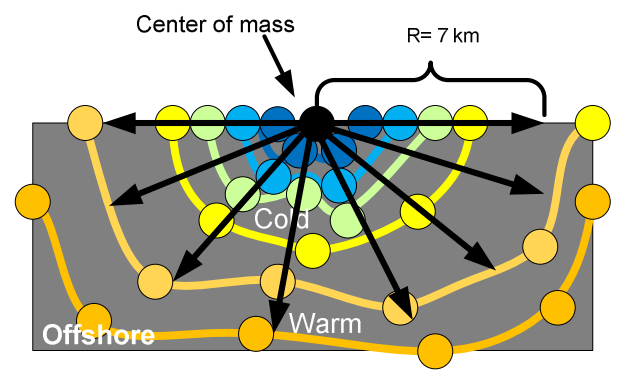

Figure 9. The upwelling detection model based on structure element diskshaped

\section{SUMMARY AND FUTURE WORK}

At this initial stage, we have proposed a method of combination of structural elements spatiogram and to determine the upwelling areas. Spatiogram applied to segment the dataset into a number of candidate areas of upwelling, while the structure element method is applied to detect whether the candidate is indeed the case in areas of upwelling or not.

Determination of upwelling is implemented using a diskshaped structure elements and radial detection to determine all pixels around the center of mass within a radius of $7 \mathrm{~km}$. Center of mass as the starting point of the calculation is determined based on the lowest temperature in candidate of the regions of interest.

For further research, we will develop a mathematical model of this proposed model. To determine its performance in predicting the upwelling region, it is needed to observe the study area intensively to obtain its unique features in the study area.

\section{REFERENCES}

[1] A. Chaudhuri, A. Gangopadhyay, R. Balasubramanian, and S. Ray. "Automated oceanographic feature detection from high resolution satellite images", Proceeding Computer Graphics and Imaging (CGIM 2004), August 17-19, 2004, Hawaii, USA

[2] D.M. Hakim, K. Wikantika, N. Widiadnyana, A.M. Napitu, S. Darmawan. "The identification of fishing ground area with modis satellite image (case study: south coast of West Java)", PROC. ITB Eng. Science Vol. 38 B, No. 2, 2006, 147-158.

[3] Kunarso, S. Hadi, N.S. Ningsih, M.S. Baskoro. "Variabilitas suhu dan klorofil-a di daerah upwelling pada variasi kejadian ENSO dan IOD di perairan selatan Jawa sampai Timor", ILMU KELAUTAN September 2011. Vol. 16 (3) 171-180 ISSN 0853-7291

[4] R.B. Yoga B., H. Setyono , G. Harsono. "Dinamika upwelling dan downwelling berdasarkan variabilitas suhu permukaan laut dan klorofila di perairan Selatan Jawa", JURNAL OSEANOGRAFI, Volume 3, Nomor 1, Tahun 2014, Halaman 57-66

[5] R. Wardani, W.S. Pranowo, E. Indrayanti. "Vertical structure of upwelling - downwelling in south of Java and Bali Seas of Indian Ocean based on seasonal salinity during period of 2004 - 2010". Depik, 2(3): 191-199, Desember 2013. ISSN 2089-7790

[6] J.F. Cayula, and P. Cornillon. "Edge detection Algorithm for SST images", Journal of Atmospheric and Oceanic Technology, 1992, 9(1), 67-80.

[7] K. Nieto, H. Demarcq, S. McClatchie. "Mesoscale frontal structures in the Canary Upwelling System: New front and filament detection algorithms applied to spatial and temporal patterns", Remote Sensing of Environment 123 (2012) 339-346 www.elsevier.com/locate/rse

[8] S.T. Birchfield, S.Rangarajan. "Spatiograms versus histograms for region-based tracking", IEEE Conference on Computer Vision and Pattern Recognition (CVPR) San Diego, California, June 2005

[9] S.T. Birchfield, S.Rangarajan. "Spatial histograms for region-based tracking”, ETRI Journal, Volume 29, Number 5, October 2007

[10] T. Prayogo. "Pemanfaatan Teknologi Penginderaan Jauh untuk Pengembangan Ekonomi Nelayan”, Berita Inderaja, Vol. II No.3, 2003, LAPAN, Jakarta 